\title{
Characterization of adipose-derived stem cells of anatomical region from mice
}

\author{
Arthur CL Luna ${ }^{1,2}$, Maria EP Madeira1,2, Thais O Conceição', José ALC Moreira', Rosa AN Laiso' \\ and Durvanei A Maria ${ }^{1,2^{*}}$
}

\begin{abstract}
Background: Stem cells constitute a group of great capacity for self-renewal, long-term viability, and multi-lineage potential. Several studies have provided evidence that adipose tissue represents an alternative source of stem cells, with the main benefit of adipose-derived stem cells being that they can be easily harvested from patients by a simple minimally invasive method and can be easily cultured. The aim of this study was to establish a culture protocol for obtaining and characterizing adipose-derived stem cells (ADSCs) from C57BL/6 J mice.

Results: The results showed that the yield, viability, and cell morphology obtained differ according to the age of isolated anatomic regions of the adipose tissue from ovarian and epididymis. The results of determination of cyclin D1 showed uniformity in the expression between different populations of ADSCs. A significant increase in the expression of caspase-3 active, was also observed in large cell populations from mice after 120 days. ADSCs were positive for mesenchymal markers CD90 and CD105, Nanog, SSEA-1, CD106, and VEGFR-1, and negative for hematopoietic markers CD34 and CD45. A large number of cells in $S+G 2 / M$ phases was also observed for both sexes, demonstrating high proliferative capacity of ADSCs.
\end{abstract}

Conclusions: We observed that the adipose tissue of C57BL/6 J mice, isolated from the studied anatomic regions, is a promising source for obtaining pluripotent mesenchymal stem cells with high viability and proliferative response.

Keywords: Adipose tissue, Caspase-3, Cyclin D1, Multipotent cells, Mesenchymal stem cells, Mice

\section{Background}

Stem cells constitute a group of great capacity for selfrenewal, long-term viability, and multilineage potential [1]. The multilineage potential of embryonic and adult stem cells from bone marrow has been characterized extensively. In spite of the potential of embryonic stem cells for medical applications, many ethical and political issues accompany their use [2,3]. Stem cells therapy and ex vivo gene delivery have provided two promising strategies for treatment of a vast array of inherited and acquired disorders. For these types of therapy, a reliable source of stem cells appears necessary. Researchers mainly work on two types of stem cells, embryonic and adult stem cells. However, immunorejection, tumorigenicity and ethical

\footnotetext{
* Correspondence: durvanei@usp.br

'Biochemistry and Biophysical Laboratory, Butantan Institute, 1500, Vital Brasil Avenue, Sao Paulo, Brazil

${ }^{2}$ Medical School, University of Sao Paulo, 455, Doctor Arnaldo Avenue, Sao
} Paulo 01246-903, Brazil

\section{() Biomed Central}

opposition have impeded the advancement of embryonic stem cells for clinical applications [4]. Compared with embryonic stem cells, autologous adult stem cells do not raise any major ethical or immunologic problems. Sources of adult stem cells include muscle, bone marrow, blood, epidermis, brain, liver, and, more recently, adipose tissue [3]. Stem cells derived from bone marrow were able to replace damaged heart muscle in mice after myocardial infarction [5].

However, the relatively low incident small tissue volume, difficult access, and disease-related malfunction of bone marrow-derived stem cells hamper their clinical usefulness. Several studies have provided evidence that adipose tissue represents an alternative source of stem cells and is routinely available in large quantities from low-risk techniques through non-invasive liposuction. Deposits of subcutaneous adipose tissue are an affordable, abundant, and highly capable replacement, thus providing a potential reservoir of adult stem cells in each individual. Many 
research groups, working independently, have demonstrated that adipose-derived stem cells (ADSCs) are able to differentiate in vitro into multiple lineages, among them adipocytes, chondrocytes, hepatocytes, osteoblasts, and endothelial, epithelial, hematopoietic, neuronal and myogenic cells [6]. Adipocytes derived from pluripotent cells that become precursors to mesenchymal are capable to turn into chondroblasts, osteoblasts, myoblasts or preadipocytes closely with vascular cells, stroma and extracellular matrix and are influenced by transcription factors and exogenous hormones. The components of extracellular matrix modulate the differentiation of preadipocytes and produce adhesive molecules which provide intercellular bonds and changes in morphology and size of adipocytes [7].

The main benefit of ADSCs is that they can be easily harvested from patients by a simple, minimally invasive method, and they can be easily cultured. Moreover, adipose-derived stromal/stem cells can be propagated more rapidly, and they retain their mesenchymal pluripotency, such as, $2.3 \times 10^{8}$ cells to $120 \mathrm{~mL}, 80 \%$ confluent on the third pass [8]. Some investigations have indicated that ADSCs possess different surface epitopes and differentiation potential according to the localization of the fat pad from which the cells were derived. Epicardial adipose-derived cells tend to have a short population doubling time ( $45 \pm 9.6$ hours) than the epididymis adipose-derived stem cells (69 \pm 16 hours). There are differences among deposits of ADSCs in different anatomic sites regarding their proliferative capacity and aging in vitro [9]. ADSCs from ovarian and epididymis have not yet been characterized. Therefore, the aim of this study was to establish a protocol for obtaining and characterization of ADCSs from male and female mice at different ages.

\section{Results}

\section{Isolation and culture}

The samples of adipose tissue from ovarian and epididymis of different experimental groups were digested and cultured. During the initial days after plating, stem cells isolated from adipose tissue adhered to the surface of the culture plastic plates as a small cell population or polygonal spindle shaped forming a cells monolayer. The ADSCs proliferated rapidly in vitro, forming a homogeneous composition in monolayer, with fibroblast-like morphology (Figure 1). No difference was observed in fibroblast-like morphology presentation between large and small adipocyte obtained. The yield, morphology, and viability of cells obtained differed according to the age of tissue isolated from mice.

Male mice 30 days showed an average of $1.2 \pm 0.2 \times 10^{5}$ cells in $0.21 \mathrm{~g}$ of tissue while in the group of female mice of same age, the average obtained was $1.5 \pm 0.9 \times 10^{5}$ in $0.24 \mathrm{~g}$ of tissue. In male mice 90 days, the average was
$1.6 \pm 1.1 \times 10^{5}$ cells in $0.27 \mathrm{~g}$ of tissue while females of same age had a mean of $1.4 \pm 0.6 \times 10^{5}$ cells in $0.41 \mathrm{~g}$ of tissue. At 120 days, there was a significant increase in yield of adipose tissue in relation to the total mass. In males $28.1 \times 10^{5} \pm 6.3$ in $0.34 \mathrm{~g}$ of tissue was obtained and in females $34.3 \pm 15.2 \times 10^{5}$ cells in $0.26 \mathrm{~g}$ of tissue was obtained (Figure 2).

\section{Morphological characterization}

The different populations of ADSCs were characterized by flow cytometry, as small or large, according to distinct morphological characteristics.

In males of 30 days $37.8 \% \pm 2.5$ of small cells was obtained and $62.9 \% \pm 7.9$ of large cells, in 90 days $32.2 \% \pm 2.5$ of small cells and $69.5 \% \pm 8.5$ of large cells and in 120 days $43.4 \% \pm 9.7$ of small cells and $56.4 \% \pm 8.7$ of large cells. On the other hand, in females of 30 days, $31.9 \% \pm 8.2$ was obtained and $66.0 \% \pm 6.0$ of small and large cells respectively, in 90 days $42.5 \% \pm 10.8$ of small cells and $54.7 \pm 12.8 \%$ of large cells, and finally in 120 days, $21.2 \% \pm 6.1 \%$ of small cells and 77.3\% \pm 12.2 large cells (Figure 2).

\section{Expression of stem cells markers on adipose cell populations by flow cytometry}

The expression of CD105, CD45, CD90, CD34, CD106, VEGFR-1, Nanog, and SSEA-1 was analyzed by flow cytometry. The results for males of 30 days were $52.2 \pm$ $7.0 \%, \quad 19.3 \pm 2.6 \%, \quad 56.8 \pm 2.0 \%, \quad 5.4 \pm 4.4 \%, \quad 75.7 \pm 8.9 \%$, $83,4 \pm 10.7 \%, 62.0 \pm 12.4 \%$ and $24.9 \pm 3.9 \%$ respectively, for males of 90 days were $54.4 \pm 3.0 \%, 24.5 \pm 2.8 \%, 56.2 \pm$ $4.7 \%, \quad 6.2 \pm 3.2 \%, 81.5 \pm 12.1 \%, 83.9 \pm 14.5 \%$ and $34.8 \pm$ $8.7 \%$ respectively. The expression of SSEA- 1 in 90 days is not represented in graphs, because there was no noticeable difference compared to the previous period in both sexes. For males in 120 days were $59.9 \pm 14.9 \%, 9.4 \pm 1.0 \%$, $75.8 \pm 3.7 \%, 12.7 \pm 2.5 \%, 75.7 \pm 5.9 \%, 79.3 \pm 18.2 \%, 34.0 \pm$ $9.1 \%$ and $12.7 \pm 2.5 \%$, respectively (Figures $3 \mathrm{~A}$ and 4 ). In females, the expression in the group of 30 days was $56.2 \pm$ $6.3 \%, 5.6 \pm 0.9 \%, 49.7 \pm 10.6 \%, 11.3 \pm 1.5 \%, 80.4 \pm 13.1 \%$, $39.5 \pm 10.1 \%, 77.0 \pm 10.9 \%$ and $26.6 \pm 4.2 \%$. For the group of 90 days was $55.3 \pm 1.2 \%, 16.2 \pm 1.6 \%, 51.5 \pm 4.2 \%, 9.7 \pm$ $1.7 \%, 79.3 \pm 10.9 \%, 52.1 \pm 17.7 \%$ and $83.4 \pm 17.8 \%$, and females of 120 days, $65.1 \pm 5.6 \%, 8.8 \pm 0.5 \%, 61.1 \pm 4.2 \%$, $10.5 \pm 2,1 \%, \quad 84.3 \pm 17.7 \%, \quad 51.1 \pm 12.7 \%, 42.5 \pm 9.7 \%$ and $14.7 \pm 2.9 \%$, respectively. The difference among the positivity for expression of mesenchymal and hematopoietic markers was significant $\left({ }^{* *} \mathrm{p}<0.001\right)$ (Figures $3 \mathrm{~B}$ and 4 ).

\section{Expression of cyclin D1 and caspase-3 active by flow cytometry}

The results of expression of cyclin D1 showed homogeneity increased among different populations of ADSCs and between small and large cells from males and females. Expression of cyclin D1 in males of 30 days was $85.0 \%$ for 

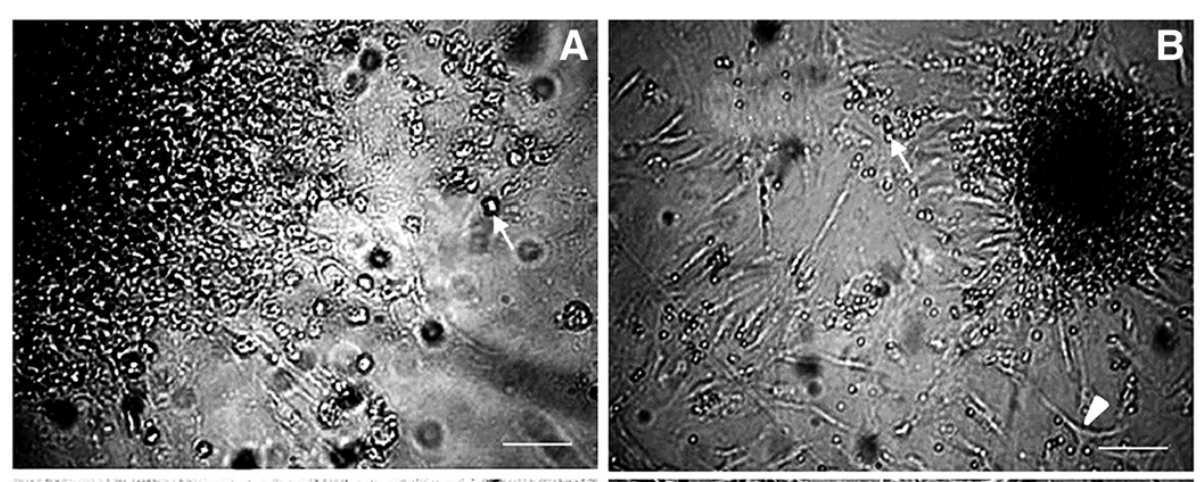

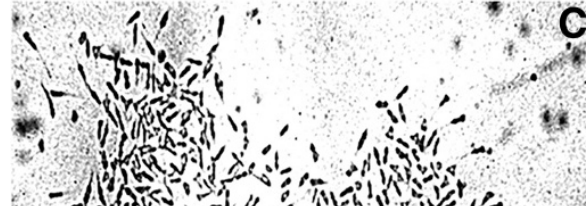

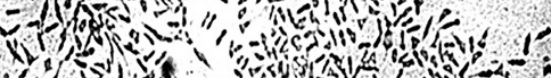
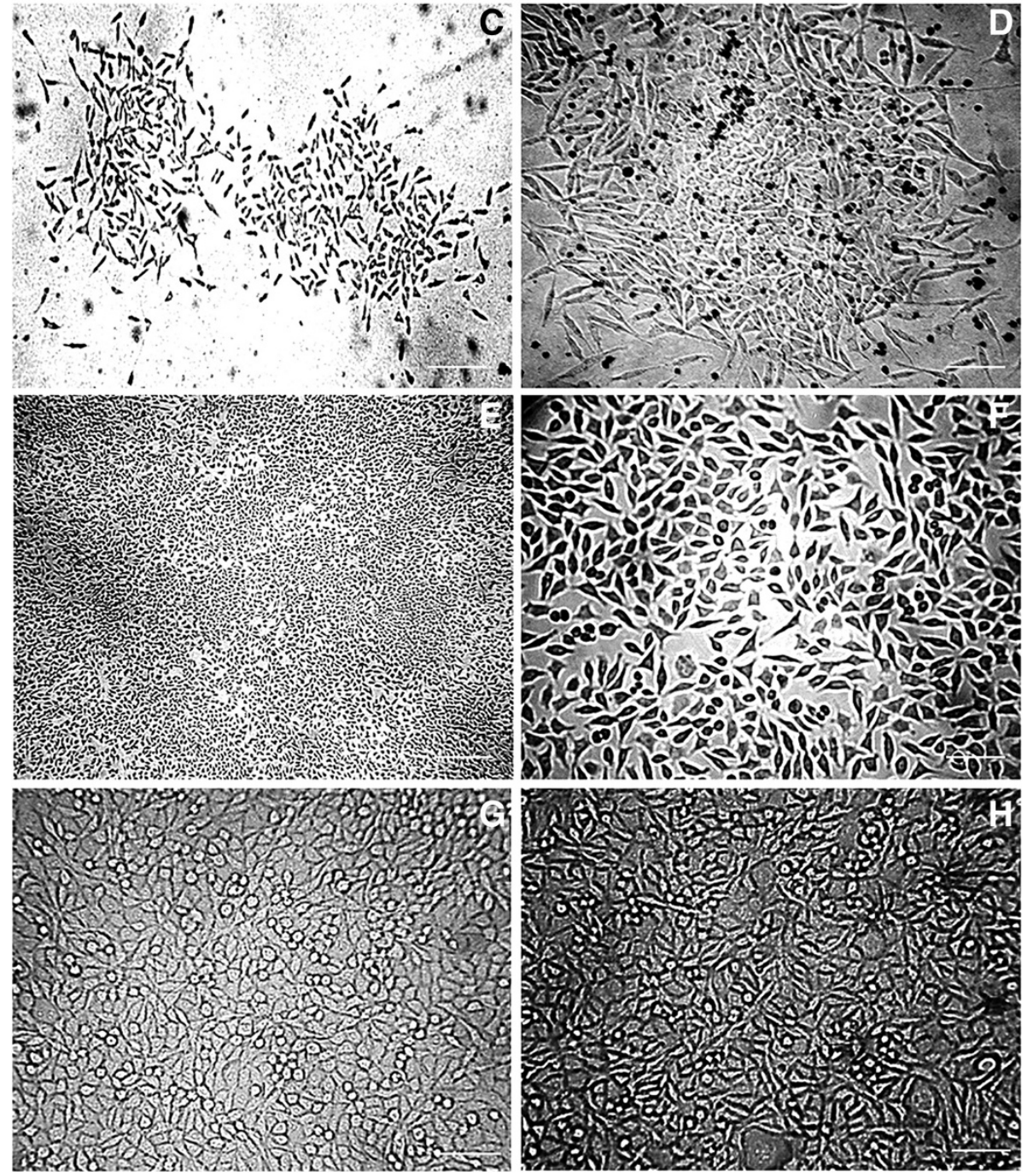

Figure 1 Adipose-derived stem cells from C57BL/6 mice observed under inverted microscopy after culture. For this study, were utilized 10 animals for sex, and experimental period of 30,90, and 120 days (total of animals $=60$ ). A and B: Initial explant of ADSCs (magnification, $\times 40$ and $\times 20$ ). It was observed in the cultures of adipose tissue, cells fusiform with appearance of fibroblast-like (arrowhead) and small cells adipose refractive rounded (arrow). C and D: Culture of ADSCs after 7 days (magnification, $\times 10$ and $\times 20$ ). $\mathbf{E}$ and $\mathbf{F}$ : Culture of ADSCs after 10 days. It is possible to observe cell confluence and homogenous population (magnification, $\times 5$ and $\times 40$ ). $\mathbf{G}$ and $\mathbf{H}$ : Culture of ADSCs above three passages on tissue culture plastic (magnification, $\times 20$ ). Cell confluence was observed and homogenous population with small and lager cells in this period. 


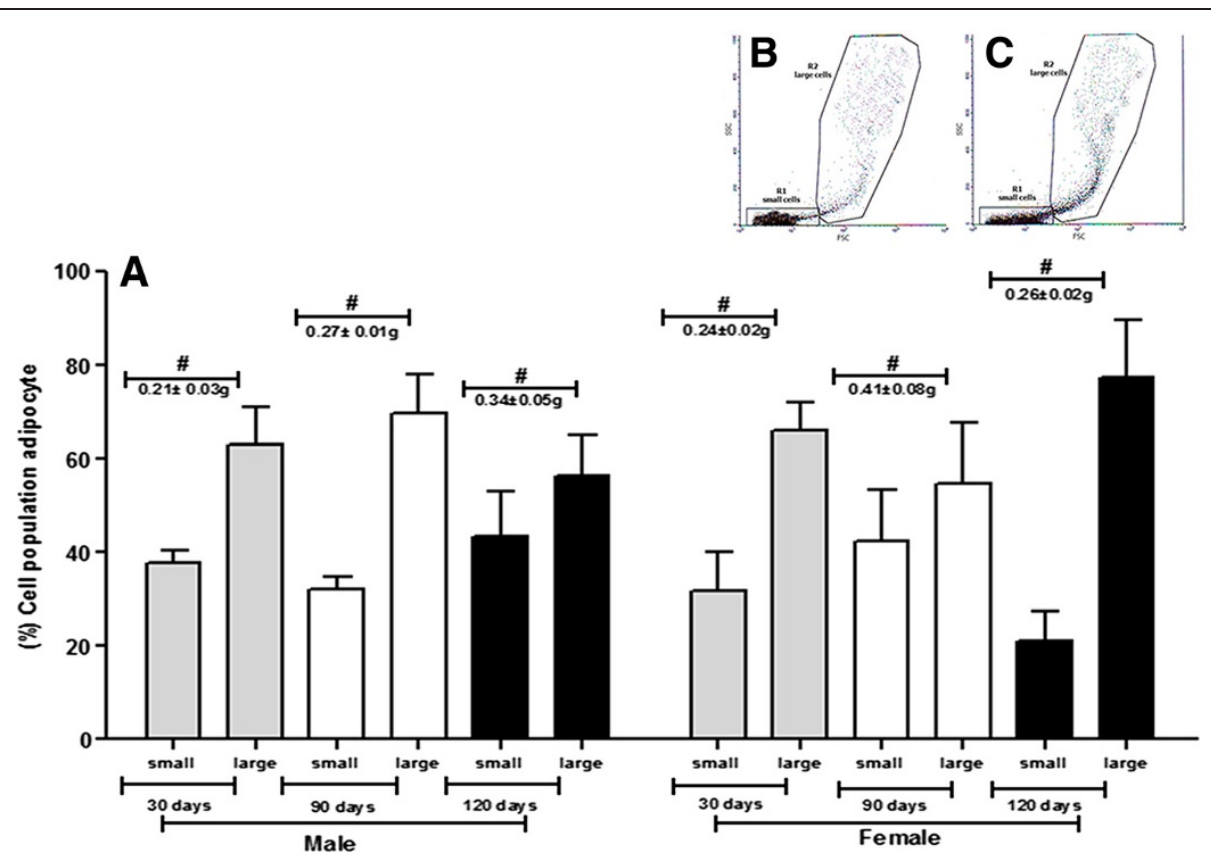

Figure 2 Cell populations and weight of tissue (g) of ADSCs from C57BL/6 J mice males and females. For this study were utilized 10 animals for sex, and experimental period of 30,90 and 120 days (total of animals $=60$ ). Results represent means \pm S.D. from three independent experiments of each experimental group (days and sexes) in triplicate. A: The graph shows the cell yield acquired of ADSCs from C57BL/6 J mice males and females among 30,90, and 120 days of age, subdivided into morphological group of small or large, after characterization by flow cytometry. Tissue weight (\#). Statistical differences were obtained by analysis of variance ANOVA and Tukey-Kramer multiple-comparisons test. No significant difference was seen in the groups. B (Male 30 days) and C (Female 30 days): The scatter plot of FSC vs. SSC shows the subdivided into morphological group of small or large, after characterization by flow cytometry.

small cells and $84.2 \%$ for large cells; for the group of 90 days, it was $82.2 \%$ and $89.9 \%$ for small and large cells, respectively; and in the group of 120 days it was $83.5 \%$ for small cells and $86.4 \%$ for large cells. On the other hand, in females of 30 days, $82.3 \%$ and $83.7 \%$ was obtained for small cells and large cells, respectively, for the group of 90 days it was $82.9 \%$ for small cells and $84.9 \%$ for large cells, and finally for the group of 120 days, $81.2 \%$ of small cells and $87.3 \%$ of large cells (Figure 5).

Expression of caspase- 3 active for males of 30 days was $17.4 \%$ for small cells and $17.3 \%$ for large cells, for the group of 90 days, $13.5 \%$ for small cells and $18.7 \%$ for large cells, and for the group of 120 days, $15.7 \%$ and $31.7 \%$ for small cells and large cells, respectively. In females of 30 days, the expression was $15.8 \%$ for small cells and $12.9 \%$ for large cells, in 90 days it was $14.1 \%$ for small cells and $15.8 \%$ for large cells, and finally, in 120 days it was $14.7 \%$ for small cells and $28.5 \%$ for large cells (Figure 6).

\section{Cell cycle phases distribution}

At 30 days, accumulated cells in G0/G1 phase were observed, in which a large number of cells were found, being 68.3\% for males and $72.4 \%$ to females. At 120 days, there was a decrease of cells in this phase, being $51.3 \%$ for males and $57.1 \%$ for females. In the synthesis phase, there was an increased number of cells. Regarding S/G2/M phases, there was a higher cell concentration for males at 30 days, with $47.5 \%$ and for females $27.6 \%$. At 120 days the results for the same phases were inversely proportional for both sexes, compared to the previous period. While in the subhaploid population in 30 days, there was a similar proportion for both sexes, with $9.2 \%$ for males and $8.5 \%$ for females. However, in 120 days there was an increase in the number of cells in the sub-haploid (Figure 7).

\section{Discussion}

Research shows that human adipose tissue obtained from liposuction is an abundant and an available source of ADSCs and can be used for research purposes. Stem cells from adipose tissue were first isolated from collected fragments of rodent adipose tissue through open surgery. Later, several groups have reported the isolation of human ADSCs taking advantage of liposuction aspirate as a tissue source [9]. The ADSCs cells display a reproducible and consistent phenotype based on cell-yield viability, adipocyte differentiation, and cell-surface marker phenotype. In this work, the use of mechanical and enzymatic techniques to isolate ADSCs from mice, proven to be effective once an adherent single cells layer were obtained, acquired a fibroblast-like morphology, this being one characteristic of mesenchymal stem cells. The characterizations of 

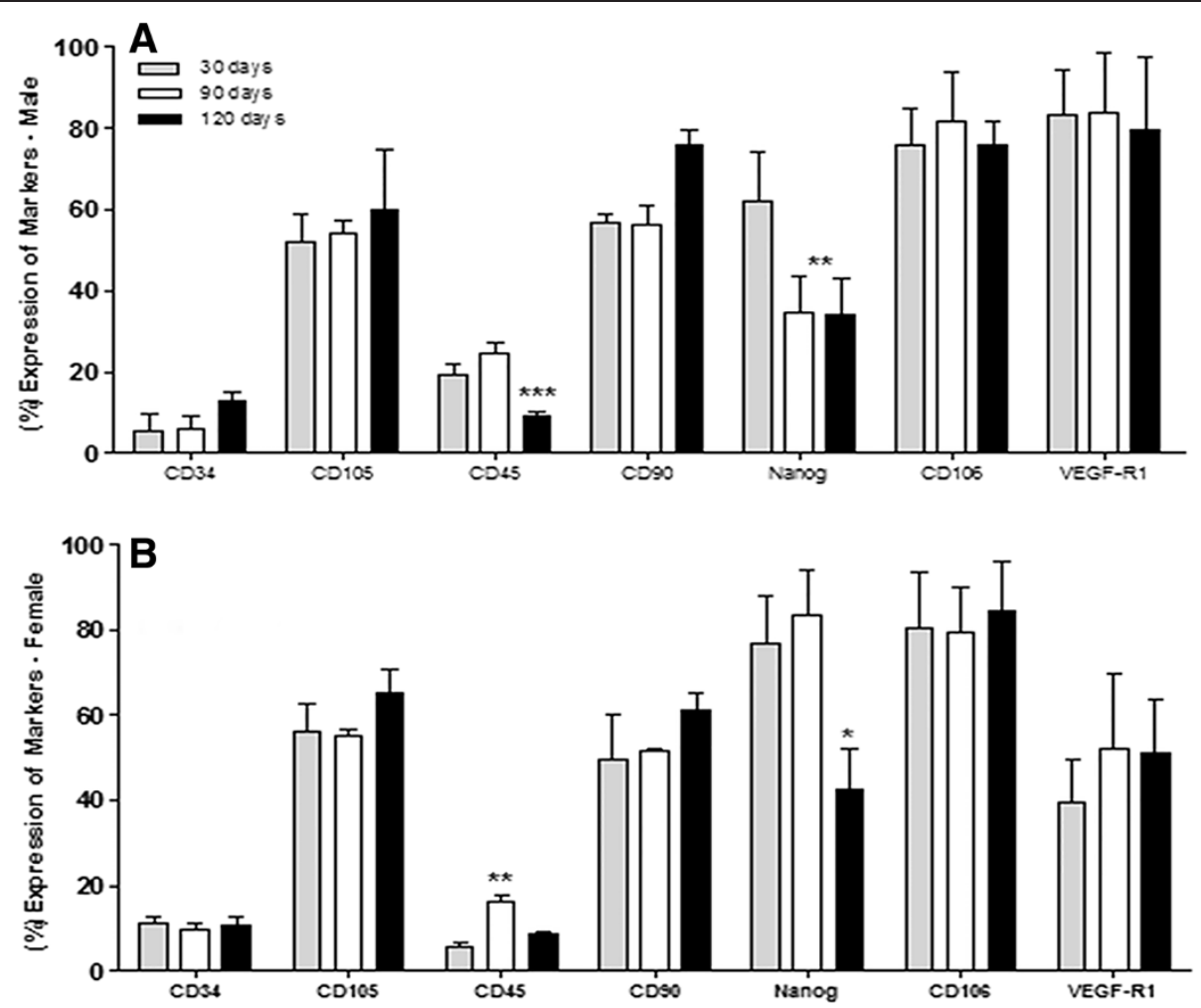

Figure 3 Analysis of stem cell markers expression of ADSCs from C57BL/6 J mice males and females. Results represent means \pm S.D. from three independent experiments of each experimental group (days and sexes) in triplicate, obtained by flow cytometry analysis. The percentages of ADSCs mice males (A) and females (B) among 30, 90, and 120 days of age expressing hematopoietic stem cell markers (CD45 and 34), mesenchymal (CD90 and CD105), Nanog, CD106, and VEGFR-1 were correlated with the age and sex of animals. The difference between the positivity for expression of mesenchymal and hematopoietic markers was statistically significant. Statistical differences were obtained by analysis of variance ANOVA and Tukey-Kramer multiple-comparisons test. Statistical significance ( $p$-value) ${ }^{*} p<0.05,{ }^{* *} p<0.01$ and ${ }^{* * *} p<0.001$.
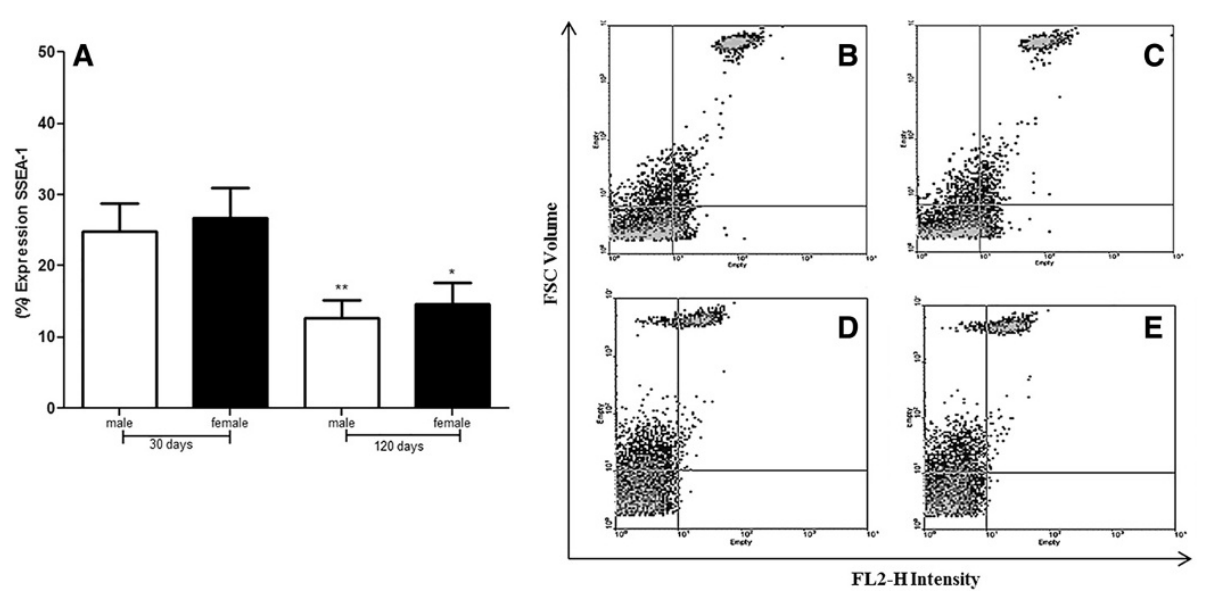

Figure 4 Analysis of SSEA-1 expression of ADSCs from C57BL/6 J mice males and females. Results represent means \pm S.D. from three independent experiments of each experimental group (days and sexes) in triplicate, obtained by flow cytometry analysis. A: The graph shows ADSCs from mice males and females between 30 and 120 days of age characterized by flow cytometry compared with SSEA-1 expression. B, C, D, and E: A single fluorescent dye was used for a dot plot vs. FSC to visualize the expression of the markers of SSEA-1. B: SSEA-1 expression at female 30 days; C: SSEA-1 expression at female 120 days; D: SSEA-1 expression at male 30 days; E: SSEA-1 expression of male 120 days. Statistical differences were obtained by analysis of variance ANOVA and Tukey-Kramer multiple-comparisons test. Statistical significance $(\mathrm{p}-\mathrm{value}){ }^{*} \mathrm{p}<0.05$ and ${ }^{* *} p<0.01$ 


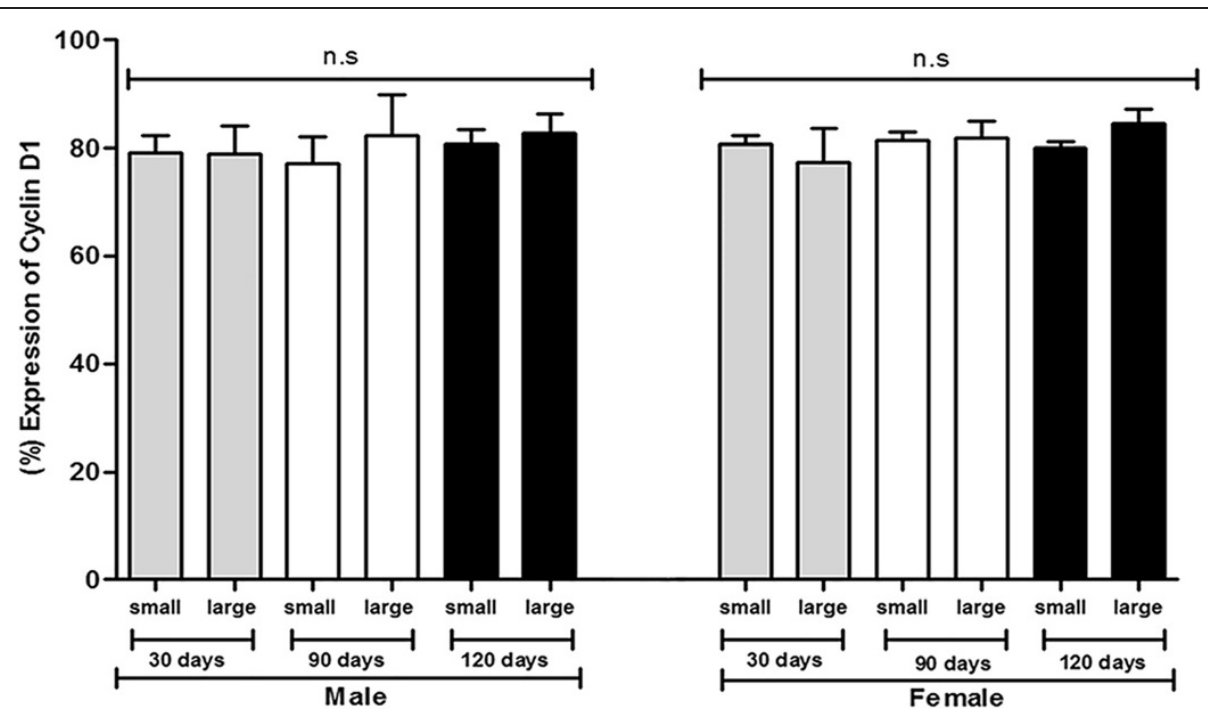

Figure 5 Analysis of cyclin D1 expression of ADSCs from C57BL/6 J mice males and females. Results represent means \pm S.D. from three independent experiments of each experimental group (days and sexes) in triplicate, obtained by flow cytometry analysis. The graph shows ADSCs from mice males and females among 30,90, and 120 days of age subdivided into morphologically large and small cells after characterization by flow cytometry compared with cyclin D1 expression. Statistical differences were obtained by analysis of variance ANOVA and Tukey-Kramer multiple-comparisons test. No significant (ns) difference at the groups.

fibroblast-like morphology have been used as criteria in assessing the potential difference of stem cells of mesenchymal origin $[10,11]$.

In this study, during the first days after culture, ADSCs adhered to the flask surface, as a small or fusiform population of polygonal cells. The ADSCs expand easily in vitro and exhibited a homogeneous fibroblast-like morphology.
The cells were sub-cultured within 1-2 days, when cells became $90 \%$ confluent.

The yield of ADSCs was expressive with an average of $87.0 \%$, and cell viability greater than $94.0 \%$. The data showed that the number of ADSCs and viability acquired from mice at different ages was greater than that obtained in recent studies. These studies showed that

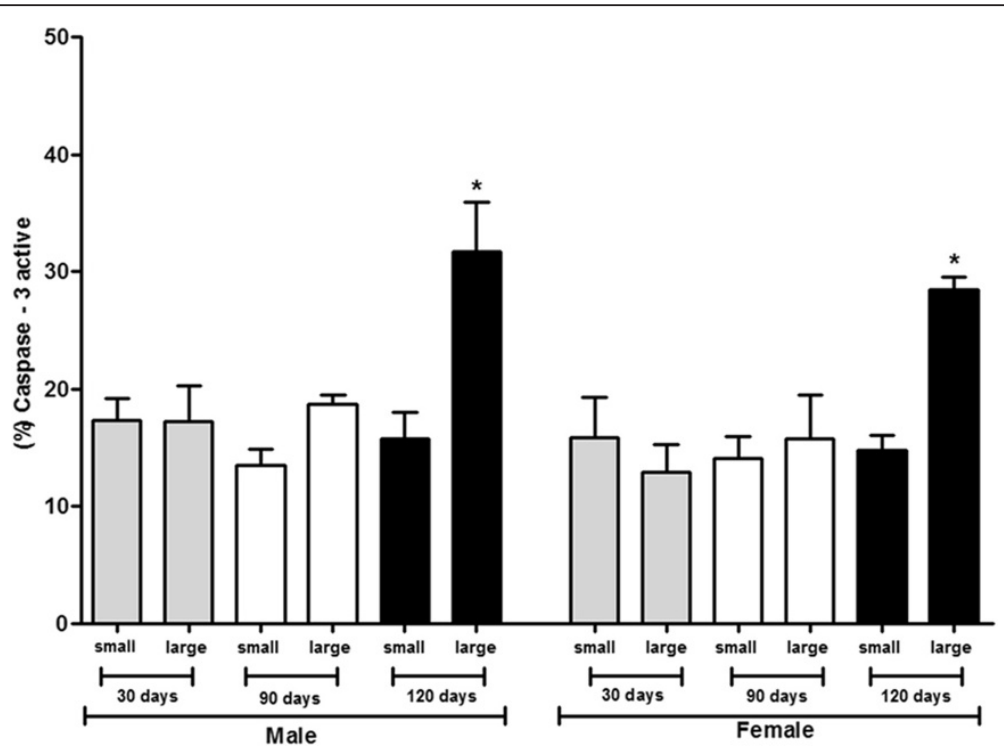

Figure 6 Analysis of caspase-3 active expression from ADSCs from C57BL/6 J mice males and females. Results represent means \pm S.D. from three independent experiments of each experimental group (days and sexes) in triplicate, obtained by flow cytometry analysis. The graph shows ADSCs from mice males and females among 30,90, and 120 days of age subdivided into morphologically large and small cells after characterization by flow cytometry compared with caspase-3 active expression. Statistical differences were obtained by analysis of variance ANOVA and Tukey-Kramer multiple-comparisons test. Statistical significance ( $p$-value) ${ }^{*} p<0.05$. 


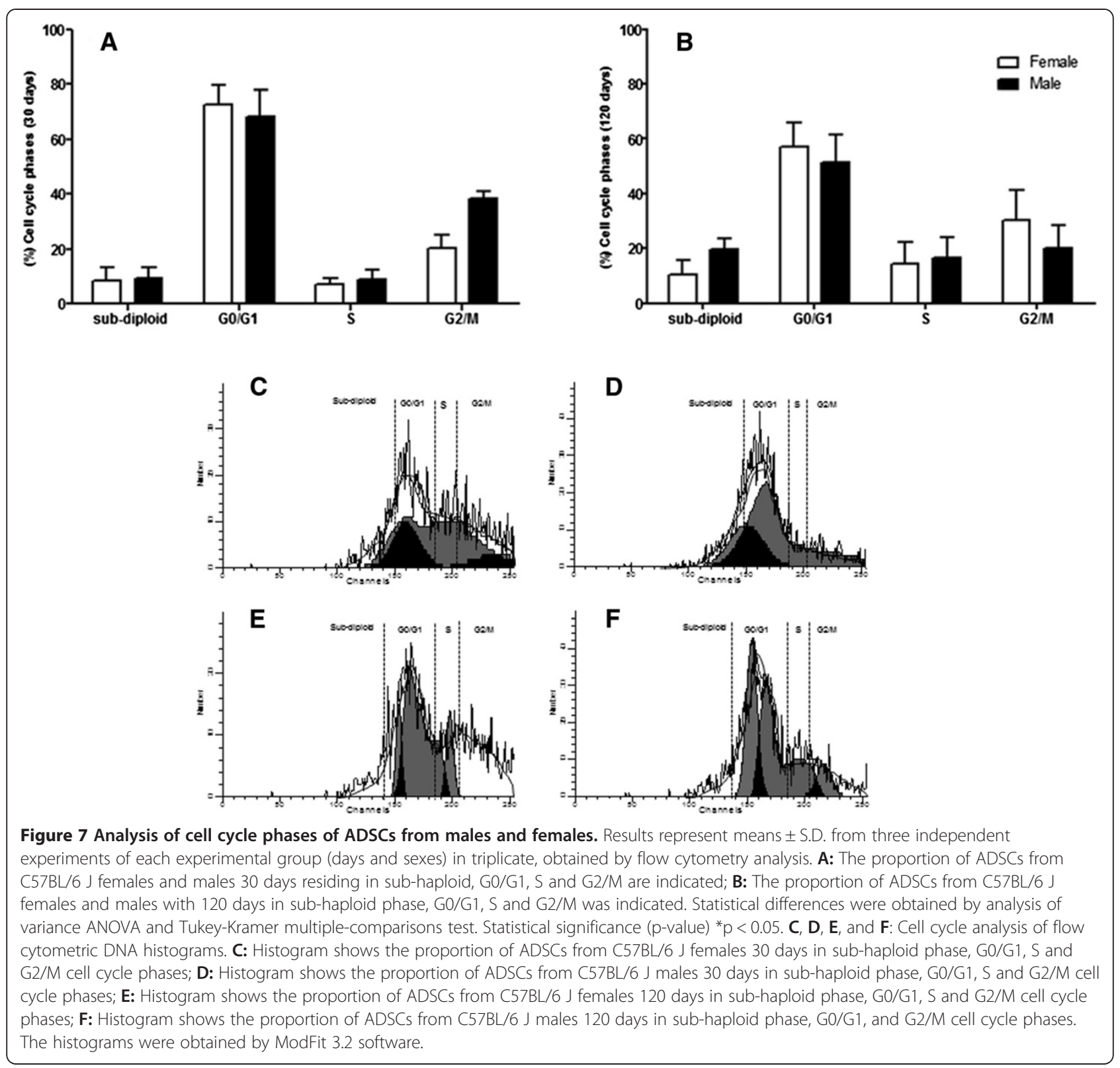

$1 \mathrm{~g}$ of adipose tissue can yield approximately $4-5 \times 10^{6}$ cells, including $1 \times 10^{6}$ adipocytes, $1 \times 10^{6}$ ADSCs, $1 \times 10^{6}$ vascular endothelial cells, and $1 \times 10^{6}$ other cells. [12,13]. Our group obtained recently stem cells of synovial membrane from equines and the data corroborate in ADSCs yield (data not shown). When comparing the results with the number of cells that can be obtained from human adipose tissue, acquired by liposuction, there were higher mean values in this study. About $2.0 \%$ of human lipoaspirate are ADSCs, or in $10 \mathrm{~g}$ of adipose tissue, about $0.2 \mathrm{~g}$ of mesenchymal stem cells could be isolated and used to perform cell therapy because these cells possess a large capacity to expand in culture, even accounting for a small fraction of adipose tissue [14]. The isolation of adipose tissue from infundibulum of ovarian, epididymis, and proximal regions showed significant cell yield compared to other studies [15-17] and satisfactory viability when compared with results obtained in humans, which was about $93.9 \pm 3.3 \%$ based on test trypan blue exclusion [15].

The weight of tissue and amount of isolated cells differed according to the age and sex of animals. It was observed that females 90 days showed higher accumulation of adipose tissue in studied regions compared with males of the same age, however, at 30 and 120 days, the males showed a higher amount of adipose tissue than females. Comparing the cell yield with sex and age of animals, it was observed that there was a significant increase in 
relation to age, represented mainly by large cell populations. However, there was no relation among the weight of adipose tissue, the amount of cells obtained, cell morphology, and age of animals.

The amount and anatomical region of stored fat differs in females and males. Females tend to have a higher body fat content, localized subcutaneously, while males have less total body fat and their adipose tissue predominates in the visceral region. Estrogen is a major factor involved in this sexual dimorphism as it promotes subcutaneous fat accumulation, has anti-inflammatory properties, and is a strong regulator of appetite and energy expenditure [18]. Estrogen regulates the amount of white adipose tissue (WAT) in females, but its role in males and whether WAT effects involve expression of estrogen receptoralpha $(E R-\alpha)$ or receptor-beta $(E R-\beta)$ were as yet unclear $[19,20]$.

Mesenchymal stem cells (MSCs) have no expression for hematopoietic surface markers CD34, CD45, and CD14 and endothelial cells CD31, and are positive for STRO-1, CD29, CD73, CD90, CD105, CD166, and CD44 [21]. The data obtained in this study showed that the cells studied exhibit significant expression of mesenchymal markers CD90 and CD105, corroborating other results [22], and low expression of hematopoietic markers CD34 and CD45. Thus, the results suggest that mesenchymal stem cells were isolated from adipose tissue of mice.

The expression of CD105 and CD34 increased significantly with enhanced VEGF expression [23]. Expression of markers CD9, CD29, CD44, CD49d, and CD106 interfere with the proliferation and differentiation of hematopoietic stem cells. Preliminary studies indicated that adipose tissue-derived stromal cells are capable of supporting hematopoiesis in vitro [24].

The markers did not differ in relation to the sex of animals. However, there was a higher positivity of markers in large-cell populations, as well as the findings of other authors [25], who observed that large cells showed higher expression of markers of mesenchymal cells. It was observed that at mice 120 days there was a decrease in the expression of markers of mesenchymal cells in both sexes and a not very significant increase in expression of hematopoietic markers. The increase of these markers may be explained at this age for a period of maturation of ADSCs, causing the greatest potential for hematopoietic cells.

According to reports in the literature about stem cells derived from stromal vascular fraction (SVF) of adipose tissue, up to three passage, has distinct populations of cells divided into small and large stem cells, supporting results obtained from ovarian and epididymis. Following adherence of the SVF to tissue culture flasks (MSCs, passage 1) the immunophenotype became more homogenous for both the large and small cells [25]. In literature, $53.0 \%$ of mesenchymal large cells exhibit $79.0 \%$ viability; whereas $47.0 \%$ of small cells have $94.0 \%$ viability, thus, the size of mesenchymal cells interferes with cell viability [25]. In our study, were observed the existence a significant increase in the expression of caspase- 3 active at 120 days, in large cells populations, demonstrating that during this period the activation of apoptosis occurs, which may be a balance mechanism of the cell number when they reach maximum potential of maturation. Regarding the expression of cyclin D1, no significant difference was seen among markings in populations of ADSCs and between sexes.

Researchers described that the age is a limiting factor for the use of adult stem cells due to accumulation of intrinsic events, such as DNA mutations, as well as the extrinsic (changes in the stem cell niche). It is assumed that, with advancing age, the mechanism responsible for suppression of development of tumors, such as senescence and apoptosis, may induce a decline of multiplicative function of stem cells [26]. Various intrinsic programs and pathways facilitate the unique characteristics of stem cells, and these programs, in charge of everything maintenance, to proliferation, to eventual differentiation of the stem cells, have to be tightly controlled by the microenvironment [27].

In early G1-phase, cyclin-D family comes together in a holoenzyme complex with one or two catalytic subunits of cyclin-dependent kinases (CDKS), Cdk4 e Cdk6 [28]. Analysis of cell cycle phases that the age represents, for both sexes, showed that the major cell populations are in G0/G1, corroborating the expression of the cyclin-D1. However, in 120 days there was a decrease in the phases G0/G1 for both sexes. A large number of cells were observed in phases $\mathrm{S}+\mathrm{G} 2 / \mathrm{M}$, for both sexes, demonstrating high proliferative capacity of the ADSCs, as we discussed previously. However, in 120 days an increase of cell number was observed in phase sub-haploid for both sexes. This increase demonstrates the loss of cell viability, also evidenced by the significant increase of the caspase-3 in the same period. Most cells with subhaploid DNA content correspond to apoptotic cells with fragmented DNA or condensed chromatin [29]. This process may result in the presence of cellular debris and nucleus containing small amounts of DNA [30]. Then, the fraction sub-haploid quantified in flow cytometry may contain, in addition to apoptotic cells, cellular and nuclear fragments, nucleus or micronucleus with normal content of DNA, but containing a different chromatin structure [31].

In early embryonic development, cell fate is regulated by the core transcription factor network, which includes octamer-binding transcription factor 4 (Oct-4), sex determining region Y-box2 (Sox-2), homeobox protein Nanog, signal transducer and activator of transcription 3 (Stat-3), and some other factors [32]. Nanog is the first transcription 
factor that is restricted to the inner cell mass after compression [33]. Nanog represses embryonic ectoderm differentiation but has little effect on other lineages, whereas Sox-2 and Sox -3 are redundant and repress mesendoderm differentiation [34]. Nanog has been detected only in proliferating cells, but not in MSCs induced to differentiate. The percentage of cells expressing Nanog was maintained throughout early passages of MSCs, but then started to decrease in late passages in MSCs from adipose tissue and heart but not from bone marrow [35]. We found that Nanog expression was positive for both sexes and ages. Expression of Nanog for females of 90 days increased significantly compared with males of the same age. At the preimplantation stage, murine embryos, human germ cells, and teratocarcinoma stem cells express certain molecular receptors known as Stage Specific Embryonic Antigens (SSEA) on their membrane surface [36]. SSEA-1 and Nanog occur in embryonic stem cells; both have an important role in maintaining the capacity for self-renewal [37]. Thus these markers have been used to characterize mouse and human embryonic stem cells [38]. The expression of SSEA-1 in the cells supports the marking of Nanog, being positive in both sexes and ages analyzed, but there was no significant difference between sexes. Cell culture at 90 days is not represented in the graphs because there was no noticeable difference compared to the previous period. There was a significant decrease in SSEA-1 expression for both sexes. These results indicate that these cells are pluripotent and the method for establishing them is feasible. The literature showed in histological and cytometric analyzes that SSEA-1 was expressed at high levels in ADSCs. In ADSCs cultured, at passage 0 , it was expressed at a higher level than CD34 [39]. Gender differences were found to affect the osteogenic capacity of ADSCs, with ADSCs from males differentiating more rapidly and more effectively than ADSCs from females in vitro; the adipogenic potential was unchanged irrespective of age, while the osteogenic potential appears to decrease with increasing age. These differences are likely due to the different steroid functions in males and females with hormone levels ranging at different phases of life [35].

Members of the VEGF family show different affinities for one of three VEGF tyrosine kinase receptors: VEGF $\mathrm{R}-1, \mathrm{R} 2$, or R3 [40]. Studies targeting genes in mice have shown the importance of VEGFs and VEGFRs in the development of the vascular system [41]. Despite a high degree of homology within the kinase domains, the signaling properties of different VEGFs greatly differ. The fact that VEGFR-1be is usually expressed at low levels has hampered progress in elucidating its signal transduction pathways. VEGFR-1 has been shown to mediate monocyte migration, recruitment of endothelial cell progenitors, hematopoietic stem cell survival, and release of growth factors from liver endothelial cells $[42,43]$. VEGFR-1 is a positive regulator of monocyte and macrophage migration, and has been described as a positive and negative regulator of VEGFR-2 signaling capacity. Moreover, the migration of hematopoietic progenitor cells, as well as monocytes, towards a gradient of VEGF is mediated through VEGFR-1 [41]. The results of the determination of VEGFR-1 showed uniformity in the expression between 30 and 120 days of age, however, receptor expression in females is significantly decreased compared with males of the same age. The high VEGFR-1 expression can be explained by the change in adipose tissue because it is one of the most vascularized tissues of the body, and a close functional relationship exists between fat tissue and its vasculature.

Other studies have reported the involvement of VEGFR-1 signaling in fat tissue formation. For example, mice deficient of placenta-derived growth factor (PIGF, specific ligand for VEGFR-1) have lower body weights during the later stages of diet-induced obesity. However, pharmacologic inhibition of PlGF had no apparent effect and adipogenesis is dependent on VEGF-mediated formation of new blood vessels [44]. MSCs can also increase angiogenesis. Rats treated with MSCs had significant increases in numbers of newly formed capillaries at the boundary of the ischemic lesion in rats treated with human MSCs. Decreased VEGFR-1 expression in females when compared to males may be related to the pregnancy period. In rats, mRNA for $\mathrm{VEGF}_{164}$ is increased during pregnancy (5.0 fold increase on 12th day) and during lactation (18.5-fold increase on 7th day). VEGF ${ }_{120}, 165$ and 188 amino acid isoforms are expressed during pregnancy, lactation, and involution, and their abundance relative to one another does not alter during the mammary gland cycle. In mice, there is an increase in VEGF mRNA levels during the phase of lactation (maximal 9.7-fold at 7th day); levels of VEGF decreased progressively during the phase of involution. In relation to VEGFR-1 and VEGFR-2, a quantitative analysis in the rat mammary gland revealed an increase in VEGFR-2 during pregnancy (1.6- fold at 4th day). During lactation, VEGFR-1 (2.7fold at 7th day) and VEGFR-2 (3.8- fold at $7^{\text {th }}$ day) increased [45].

The reproducibility and consistency of these primary human cells support their value as an adult stem cell model, and may be used with great potential in basic research and preclinical studies. Several studies have demonstrated the potential of these stem cells. ADSCs were able to improve peripheral nerve regeneration in vivo when compared with no conduits cells [46]. The ability to isolate a consistently homogeneous population of undifferentiated adult stem cells from adipose tissue from studied anatomical regions, supports their potential utility in future tissue-engineering applications. Adipose tissue represents a precious source of multipotent cells with a great potential for several clinical applications, above all in the field of regenerative medicine 
[11]. ADSCs have the relative advantages of accessibility and abundance. This means that there is less pain to the patient in obtaining the cells and it is easy to obtain a sufficient quantity of cells.

\section{Conclusion}

The use of mechanical and enzymatic techniques to isolate ADSCs of mice is proven to be an effective method, once an adherent single cells layer was obtained. The data showed that number of ADSCs, and viability, acquired from adipose tissue of mice, at different ages and different anatomical sites, is greater than that obtained in recent studies. The high VEGFR-1 expression can be explained by must be change the adipose tissue because it is one of the most vascularized tissues of the body and a close functional relationship exists between fat tissue and its vasculature. The data obtained in this study showed that cells studied exhibit significant expression of mesenchymal markers CD90 and CD105 and pluripotency markers Nanog, SSEA-1, as well as a marker of proliferation potential Nanog. These results indicate these cells are pluripotent and that the method for establishing them from ADSCs is feasible. The results suggest that adipose tissue, isolated from the studied regions is a promising alternative source of stem cells. The yield and cell viability of the ADSCs acquired in this study make these cells a potential source in tissue engineering applications.

\section{Methods}

\section{Animals}

All experiments protocols were approved by ethics committee on animal use from Butantan Institute. For this study, 60 animals were used. Adipose tissue was collected from normal mice C57BL/6 J, males and females of 10 mice/ group (aged 4 to 16 weeks old), weighing between 20-25 g, from Central Bioterium of Butantan Institute, São Paulo, Brazil. The animals were sacrificed in accordance with the standards described in Use of Experimental Animals at Johns Hopkins - Guide to the Care and Use of Experimental Animals.

\section{Isolation and culture of ADSCs}

In sterile conditions, under laminar flow, the abdominal cavity was exposed and adipose tissue was isolated from regions close to the ovarian infundibulum in females and in the lateral epididymis region in males. The tissue was mechanically separated and the material was processed under laminar flow also in such a way as to be eliminated adipose tissue subjacent, leaving the dermoadipocyte sheet impregnated in Hank's Balanced Salt Solution (HBSS) (Gibco, Carlsbad, CA, United States). The small fragments on a Petri plate of $35 \mathrm{~mm}$ were incubated with type IV collagenase $0.2 \mathrm{U} / \mathrm{ml}$ for $3 \mathrm{~h}$ at $37^{\circ} \mathrm{C}$ in $5 \% \mathrm{CO}_{2}$. Then, the collagenase was neutralized with $10 \mathrm{ml}$ of fetal bovine serum (Sigma-Aldrich, St. Louis, MO, United States), the cellular debris were removed and remaining material, consisting of vascular cells, fibroblasts and adipocytes was solubilized in HBSS and filtered through a $40 \mu \mathrm{m}$ membrane. The concentrate obtained from the previous step was centrifuged for 10 minutes at $274 \times \mathrm{g}$ and at $4^{\circ} \mathrm{C}$, the supernatant formed was aspirated, the cell pellet resuspended in $1 \mathrm{ml}$ of complete culture medium and cell culture flats were incubated containing the material. After growth and expansion, to subconfluence, the cells were resuspended in culture medium, trypsinized and filtered. The filtrate was collected on cell culture flasks containing $50 \mathrm{ml}$ of saline solution supplemented with antibiotics. Finally, cells were quantified on Malassez chamber, the concentration adjusted to $2 \times 10^{5} \mathrm{ml}$ and plated for different analyzes. ADSCs above three passages on tissue culture plastic (P3) were analyzed for surface marker expression.

\section{Characterization of ADSCs by flow cytometry}

After three passage ADSCs were detached using trypsinEDTA $0.2 \%$ (Gibco, Carlsbad, CA, United States) and were counted. Then, $3 \%$ rat serum was added to aliquots of about $2 \times 10^{5}$ cells in centrifuge tubes. The cells were incubated on ice for $30 \mathrm{~min}$, resuspended in PBS and pelleted by centrifugation for $10 \mathrm{~min}$ at $274 \times \mathrm{g}$. Then, the cells were stained with CD105 (AbD Serotec, Raleigh, NC, United States), CD45 (Sigma-Aldrich, St. Louis, MO, United States), CD90 (Abcam, Cambridge, MA, United States), CD34 (Santa Cruz Biotechnology, Dallas, TX, United States), CD106 (Becton Dickinson, San Jose, CA, United States), VEGFR-1 (Sigma-Aldrich, St. Louis, MO, United States), Nanog (Abcam, Cambridge, MA, United States) and SSEA-1 (Abcam, Cambridge, MA, United States) at a concentration of $1 \mu \mathrm{g} / \mathrm{ml}$ at $4^{\circ} \mathrm{C}$ for $30 \mathrm{~min}$. The corresponding isotope antibody was used as negative control and as a secondary antibody was used Goat anti Mouse IgG (H/L): FITC (AbD Serotec, Raleigh, NC, United States). The cells were pelleted, washed twice with PBS and fixed with 1\% paraformaldehyde. Then, fluorescence-activated cell sorting (FACS) analysis was performed on BD Biosciences FacsCalibur flow cytometer (Becton Dickinson, San Jose, CA, United States) using Cell Quest, and Win MDI 2.9 softwares was used to acquisition and histograms analysis. The small and large cells were identified by forward (FSC) and side-angle light scatter (SSC) characteristic by flow cytometry. Autofluorescence was assessed by acquiring cells on the flow cytometry without incubating with fluorochrome - labeled antibodies. Surface antigen expression was determined with a variety of directly labeled antibodies according to the supplier's recommendations. 


\section{Determination of caspase-3 active and cyclin D1 by flow cytometry}

The cellular pellet was resuspended in phosphatebuffered solution (PBS) at a concentration $5 \times 10^{5}$ cells/ $\mathrm{mL}$ and incubated for $1 \mathrm{~h}$ at $4^{\circ} \mathrm{C}$ with $1 \mu \mathrm{l}$ of specific antibodies: cyclin D1 conjugated with fluorescein isothiocyanate (Abcam, Cambridge, MA, United States) and specific antibody caspase-3 active with phycoerythrin (PE) (Abcam, Cambridge, MA, United States), in absence or presence of an Ac-Asp-Glu-Val-Asp-OHspecific inhibitor (Abcam, Cambridge, MA, United States). After this period the cells were centrifugate at $428 \times \mathrm{g}$ for $10 \mathrm{~min}$, washed twice with PBS-cold and fixed with $1 \%$ paraformaldehyde. Flow cytometer settings were established using unstaining cells. Cells were gated by forward scatter to eliminated debris. To eliminate the possible autofluorescence of ADSCs, the contribution of unstained cells in the measurement channel was removed. A minimum of 10,000 events was counted for each analysis. Cells were evaluated for cell surface proteins expression using BD Biosciences FacsCalibur flow cytometer (Becton Dickinson, San Jose, CA, United States) using Cell Quest, and Win MDI 2.9 softwares was used to create the histograms.

\section{Cell cycle phases analysis}

The cells were washed with PBS and resuspended in $300 \mu \mathrm{l}$ $0.03 \mathrm{~g} / \mathrm{l}$ trypsin, $10 \mathrm{mM}$ Tris (pH 8.0). After $15 \mathrm{~min}$ incubation at room temperature, 100ul of the neutralization solution $(0.5 \mathrm{~g} / \mathrm{l}$ trypsin inhibitor, $0.1 \mathrm{~g} / \mathrm{l}$ RNase A and $1.2 \mathrm{~g} / \mathrm{l}$ spermine) was added and incubation continued for $15 \mathrm{~min}$. After centrifugation cells were resuspended in $300 \mu \mathrm{lBS}$ and fixed by the addition of ice-cold ethanol 70\%. Prior to analysis, cells were incubated with $1.8 \mu \mathrm{g} / \mathrm{ml}$ propidium iodide solution (Sigma-Aldrich, St. Louis, MO, United States) and incubated in the dark for $30 \mathrm{~min}$. Flow cytometric analysis was performed using a BD Biosciences FacsCalibur flow cytometer (Becton Dickinson, San Jose, CA, United States) . The DNA content in the cell cycle phases (sub-haploid, G0/G1, S and G2/M) was analyzed by the Cell- Quest software and by the ModFit LT 3.2 software (Becton Dickinson, San Jose, CA, United States).

\section{Statistical analysis}

Numerical values were expressed as mean \pm standard deviation. One-way analysis of variance (ANOVA) and TukeyKramer multiple-comparisons test were performed to identify differences among measurements of the groups studied and the graphics were obtained by Prism version 5.0 and ModFit version 3.2 softwares. Statistical Significance (p-value) ${ }^{*} \mathrm{p}<0.05,{ }^{* * *} \mathrm{p}<0.01$ and ${ }^{* * * *} \mathrm{p}<0.001$.

\section{Competing interests}

The authors declare that they have no competing interests.

\section{Authors' contributions}

ACLL, TOC, MEPM, JALCM, RANL and DAM performed experiments in obtention, isolation, cell culture and flow cytometry of ADSCs, performed the statistical analysis and drafted the manuscript. DAM designed this study, planned all experiments, oversaw the project and finalized the manuscript. All authors read, approved the final manuscript and provided monetary support.

\section{Acknowledgments}

We thank the National Council for Scientific and Technological Development (CNPq), Foundation for Research.

Support of the State of São Paulo (FAPESP) - process number: 2013/05251-1, Butantan Institute, Sao Paulo, Brazil, Rennan Lopes Olio by support in graphic design and Rogerio Garcia Novo Pieri by technical assistance.

Received: 17 December 2013 Accepted: 14 August 2014 Published: 20 August 2014

\section{References}

1. He S, Nakada D, Morrison SJ: Mechanisms of stem cell self-renewal. Annu Rev Cell Dev Biol 2009, 25:377-406.

2. Pittenger MF, Mackay AM, Beck SC, Jaiswal RK, Douglas R, Mosca JD, Moorman MA, Simonetti DW, Craig S, Marshak DR: Multilineage potential of adult human mesenchymal stem cells. Science 1999, 284:143-147.

3. Zuk PA, Zhu M, Mizuno H, Huang J, Futrell JW, Katz AJ, Benhaim P, Lorenz $\mathrm{HP}$, Hendrick MH: Multilineage cells from human adipose tissue: implications for cell-based therapies. Tissue Eng 2001, 7:211-228.

4. Taha MF, Hedayati V: Isolation, identification and multipotential differentiation of mouse adipose tissue-derived stem cells. Tissue Cell 2010, 42:211-216.

5. Geng YJ, Caterina R: Adipose tissue-derived stem cells: caracterization and potential for cardiovascular repair. Arterioscler Thromb Vasc Biol 2009 29:1723-1729.

6. Gregoire FM, Smas CM, Sul HS: Understanding adipocyte differentiation. Physiol Rev 1998, 78:783-809.

7. Gesta S, Tseng YH, Kahn CR: Developmental origin of fat: tracking obesity to its source. Cell 2007, 131:242-256.

8. Filho Zotarelli IJ, Frascino LF, Greco OTG, Araújo JD, Bilaqui A, Kassis EN, Ardito RV, Bonilla-Rodriguez GO: Chitosan-collagen scaffolds can regulate the biological activities of adipose mesenchymal stem cells for tissue engineering. J Tissue Eng Regen 2013, 2:12.

9. Eslaminejad MB, Mardpour SM, Ebrahimi M: Mesenchymal stem cells derived from Rat epicardial versus epididymal adipose tissue. Iran J Basic Med Sci 2010, 14:25-34.

10. Zannettino AC, Paton S, Arthur A, Khor F, Itescu S, Gimble JM, Gronthos S: Multipotential human adipose-derived stromal stem cells exhibit a perivascular phenotype in vitro and in vivo. J Cell Physio/ 2008, 214:413-421.

11. Oedayrajsingh-Varma MJ, Van Ham SM, Knippenberg M, Helder MN, KleinNulend J, Schouten TE, Ritt MJ, Van Milligen FJ: Adipose tissue-derived mesenchymal stem cell yield and growth characteristics are affected by the tissue-harvesting procedure. Cytotherapy 2006, 8:166-177.

12. Suga H, Matsumoto D, Inoue K, Shigeura T, Eto H, Aoi N, Kato H, Abe H, Yoshimura K: Numerical measurement of viable and non-viable adipocytes and other cellular components in aspirated fat tissue. Plast Reconstr Surg 2008, 122:103-114.

13. Eto $\mathrm{H}$, Suga $\mathrm{H}$, Matsumoto $\mathrm{D}$, Inoue $\mathrm{K}$, Aoi N, Kato $\mathrm{H}$, Araki J, Yoshimura K: Characterization of structure and cellular componentes of aspirated and excised adipose tissue. Plast Reconstr Surg 2009, 124:1087-1097.

14. Kingham PJ, Kalbermatten DF, Mahay D, Armstrong SJ, Wiberg M, Terenghi G: Adipose-derived stem cells differentiate into a Schwann cell phenotype and promote neurite outgrowth in vitro. Exp Neurol 2007, 2007(207):267-274.

15. Aust L, Devlin B, Foster SJ, Halvorsen YD, Hicok K, Du Laney T, Sen A Willingmyre GD, Gimble JM: Yield of human adipose-derived adult stem cells from liposuction aspirates. Cytotherapy 2004, 6:7-14.

16. Zhu Y, Liu T, Song K, Fan X, Ma X, Cui Z: Adipose-derived stem cell: a better stem cell than BMSC. Cell Biochem Funct 2008, 26:664-675.

17. Stubbins RE, Najjar K, Holcomb VB, Hong J, Nunez NP: O estrongen alters adipocyte biology and protects female mice from adipocyte inflammation and insulin resistance. Diabetes Obes Metab 2012, 14:58-66. 
18. Nickelson KJ, Stromsdorfer KL, Pickering RT, Liu TW, Ortinau LC, Keating AF, Perfield JW 2nd: A comparison of inflammatory and oxidative stress markers in adipose tissue from weight-matched obese male and female mice. Exp Diabetes Res 2012, 859395:8.

19. Heine PA, Taylor JA, Iwamoto GA, Lubahn DB, Cooke PS: Increased adipose tissue in male and female estrogen receptor-alpha knockout mice. Proc Natl Acad Sci 2000, 7:12729-12734.

20. Meyer MR, Clegg DJ, Prossnitz ER, Barton M: Obesity, insulin resistance and diabetes: sex differences and role of estrogen receptors. Acta Physiol 2011, 203:259-269.

21. Mafi P, Hindocha S, Mafi R, Griffin M, Khan WS: Adult mesenchymal stem cells and cell surface characterization - a systematic review of the literature. Open Orthop J 2011, 5:253-260.

22. Musina RA, Bekchanova ES, Sukhikh GT: Comparison of mesenchymal stem cells obtained from different human tissues. Bull Exp Biol Med 2005, 139:504-509.

23. Yang L, Lu W, Huang G, Wang W: Correlation between CD105 expression and postoperative recurrence and metastasis of hepatocellular carcinoma. BMC Cancer 2006, 6:110.

24. Gronthos S, Franklin DM, Leddy HA, Robey PG, Storms RW, Gimble JM: Surface protein characterization of human adipose tissue-derived stromal cells. J Cell Physiol 2001, 189:54-63.

25. Shi Y, Niedzinski JR, Samaniego A, Bogdansky S, Atkinson BL: Adiposederived stem cells combined with a demineralized cancellous bone substrate for bone regeneration. Tissue Eng 2012, 18:1313-1321.

26. Sharpless NE, DePinho RA: How stem cells age and why this makes us grow old. Nat Rev Mol Cell Biol 2007, 8:703-713.

27. Pozarowski P, Grabarek J, Darzynkiewics Z: Flow Cytometry of Apoptosis. In Curr Protoc Cell Biol. ; 2004. chapther 18, unit 18.8.

28. Sherr CJ, Roberts JM: Living with or without cyclins and cyclin-dependent kinases. Genes Dev 2004, 18:2699-2711.

29. Ormerod MG: Investigating the relationship between the cell cycle and apoptosis using flow cytometry. J Immunol Methods 2002, 265:73-80.

30. Riccardi C, Nicoletti I: Analyses of apoptosis by propidium iodide staining and flow cytometry. Nat Protoc 2006, 1:1458-1461.

31. Darzynkiewicz Z, Juan G, Li X, Gorczyca W, Murakami T, Traganos F: Cytometry in cell necrobiology: analysis of apoptosis and accidental cell death (necrosis). Cytometry 1997, 1:1-20.

32. Rodda DJ, Chew JL, Lim LH, Wang B, Ng HH, Robson P: Transcriptional regulation of Nanog by OCT4 and Sox2. J Biol Chem 2005, 280:24731-24737.

33. Wang Z, Oron E, Nelson B, Razis S, Ivanova N: Distinct lineage specification roles for Nanog, OCT4 and Sox2 in human embryonic stem cells. Cell Stem Cell 2012, 10:440-444.

34. Pierantozzi E, Gava B, Manini I, Roviello F, Marotta G, Chiavarelli M, Sorrentino V: Pluripotency regulators in human mesenchymal stem cells: expression of NANOG but not of OCT-4 and SOX-2. Stem Cells Dev 2011, 20:915-923.

35. Cai X, Su X, Li G, Wang J, Lin Y: Osteogenesis: Osteogenesis of adiposederived stem cells. http://www.intechopen.com/books/osteogenesis/ osteogenesis-of-adipose-derived-stem-cells.

36. Shamblott MJ, Axelman J, Wang S, Bugg EM, Littlefield JW, Donovan PJ, Blumenthal PD, Huggins GR, Gearhart JD: Derivation of pluripotent stem cells from cultured human primordial germ cells. Proc Natl Acad Sci 1998, 95:13726-13731.

37. Song X, Li Y, Chen X, Yin G, Huang Q, Chen Y, Xu G, Wang L: bFGF promotes adipocyte differentiation in human mesenchymal stem cells derived from embryonic stem cells. Genet Mol Biol 2014, 37:127-134.

38. Buhring H, Battula V, Treml S, Schewe B, Kanz L, Vogel W: Novel markers for the prospective isolation of human MSC. Ann N Y Acad Sci 2007, 1106:262-271.

39. Lin G, Garcia M, Ning H, Banie L, Guo YL, Lue TF, Lin CS: Defining stem and progenitor cells within adipose tissue. Stem Cells Dev 2008, 17:1053-1063.

40. Ferrara N, Gerber HP, Le Couter J: The biology of VEGF and its receptors. Nat Med 2003, 9:669-766

41. Kowanetz M, Ferrara N: Vascular endothelial growth factor signaling pathways: therapeutic perspective. Clin Cancer Res 2006, 12:5018-5022.

42. Ferrara N, Davis-Smyth T: The biology of vascular endothelial growth factor. Endocr Rev 1997, 18:4-25.
43. Barleon B, Sozzani S, Zhou D, Weich HA, Mantovani A, Marme D: Migration of human monocytes in response to vascular endothelial growth factor (VEGF) is mediated via the VEGF receptor flt-1. Blood 1996, 87:3336-3343.

44. Olsson AK, Dimberg A, Kreuger J, Claesson-Welsh L: VEGF receptor signalling - in control of vascular function. Nat Rev Mol Cell Biol 2006, 7:359-371.

45. Lijnen HR, Christiaens V, Scroyen I, Voros G, Tjwa M, Carmeliet P, Collen D: Impaired adipose tissue development in mice with inactivation of placental growth factor function. Diabetes 2006, 55:2698-2704.

46. Azizi SA, Stokes D, Augelli BJ, DiGirolamo C, Prockop DJ: Engraftment and migration of human bone marrow stromal cells implanted in the brains of albino rats-similarities to astrocyte grafts. Proc Natl Acad Sci U S A 1998, 95:3908-3913.

doi:10.1186/1756-0500-7-552

Cite this article as: Luna et al:: Characterization of adipose-derived stem cells of anatomical region from mice. BMC Research Notes 2014 7:552.

\section{Submit your next manuscript to BioMed Central and take full advantage of:}

- Convenient online submission

- Thorough peer review

- No space constraints or color figure charges

- Immediate publication on acceptance

- Inclusion in PubMed, CAS, Scopus and Google Scholar

- Research which is freely available for redistribution

Submit your manuscript at www.biomedcentral.com/submit
C Biomed Central 